\title{
The Oral Bacterial Community in Melanophryniscus admirabilis (Admirable Red-Belly Toads): Implications for Conservation
}

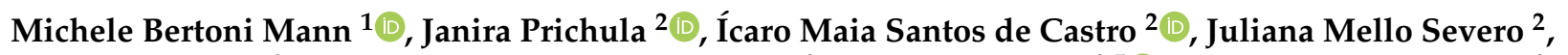 \\ Michelle Abadie $^{3}$, Thayná Mendes De Freitas Lima ${ }^{4}$, Valentina Caorsi ${ }^{4,5}{ }^{\circ}$, Márcio Borges-Martins ${ }^{4}$, \\ Jeverson Frazzon ${ }^{6}$ and Ana Paula Guedes Frazzon $1, *(1)$
}

1 Post-Graduation Program in Agricole and Environmental Microbiology, Department of Microbiology, Immunology and Parasitology, Federal University of Rio Grande do Sul, Porto Alegre 90050-170, Brazil; mbertonimann@gmail.com

2 Department of Health Sciences, Federal University of Health Sciences of Porto Alegre, Porto Alegre 90050-170, Brazil; janira.pri@gmail.com (J.P.); icaromscastro@gmail.com (Í.M.S.d.C.); juliana.bioinformatica@gmail.com (J.M.S.)

3 Biosciences Institute, Federal University of Rio Grande do Sul, Porto Alegre 91509-900, Brazil; abadie.mi@gmail.com

4 Post-Graduation Program in Animal Biology, Department of Zoology, Biosciences Institute, Federal University of Rio Grande do Sul, Porto Alegre 91509-900, Brazil; thaynamfl@gmail.com (T.M.D.F.L.); valenzc@gmail.com (V.C.); borges.martins@ufrgs.br (M.B.-M.)

Citation: Mann, M.B.; Prichula, J.; de Castro, Í.M.S.; Severo, J.M.; Abadie, M.; De Freitas Lima, T.M.; Caorsi, V.; Borges-Martins, M.; Frazzon, J.; Frazzon, A.P.G. The Oral Bacterial Community in Melanophryniscus admirabilis (Admirable Red-Belly Toads): Implications for Conservation. Microorganisms 2021, 9, 220. https://doi.org/10.3390/ microorganisms 9020220

Academic Editor: Kazunari Ushida Received: 21 December 2020

Accepted: 18 January 2021

Published: 22 January 2021

Publisher's Note: MDPI stays neutral with regard to jurisdictional claims in published maps and institutional affiliations.

Copyright: (C) 2021 by the authors. Licensee MDPI, Basel, Switzerland. This article is an open access article distributed under the terms and conditions of the Creative Commons Attribution (CC BY) license (https:// creativecommons.org/licenses/by/ $4.0 /)$.
5 Research and Innovation Centre, The Institute Agrario di San Michele all'Adige, Fondazione Edmund Mach, 138010 San Michele all'Adige, Italy

6 Biochemistry and Molecular Biology of Microorganisms Laboratory, Federal University of Rio Grande do Sul, Porto Alegre 91509-900, Brazil; jeverson.frazzon@ufrgs.br

* Correspondence: ana.frazzon@ufrgs.br

\begin{abstract}
Melanophryniscus admirabilis (admirable red-belly toad) is a microendemic and critically endangered species found exclusively along $700 \mathrm{~m}$ of the Forqueta River, in a fragment of the Atlantic Forest of southern Brazil. One of the greatest concerns regarding the conservation of this species is the extensive use of pesticides in areas surrounding their natural habitat. In recent years, the adaptation and persistence of animal species in human-impacted environments have been associated with microbiota. Therefore, the present study aimed to characterize the oral bacterial community of wild M. admirabilis and to address the question of how this community might contribute to this toad's adaptation in the anthropogenic environment as well as its general metabolic capabilities. A total of 11 oral samples collected from wild M. admirabilis were characterized and analyzed via high-throughput sequencing. Fragments of the $16 S$ rRNA variable region 4 (V4) were amplified, and sequencing was conducted using an Ion Personal Genome Machine (PGM) System with 316 chips. A total of 181,350 sequences were obtained, resulting in 16 phyla, 34 classes, 39 orders, and 77 families. Proteobacteria dominated (53\%) the oral microbiota of toads, followed by Firmicutes (18\%), Bacteroidetes (17\%), and Actinobacteria (5\%). No significant differences in microbial community profile from among the samples were reported, which suggests that the low dietary diversity observed in this population may directly influence the bacterial composition. Inferences of microbiome function were performed using PICRUSt2 software. Important pathways (e.g., xenobiotic degradation pathways for pesticides and aromatic phenolic compounds) were detected, which suggests that the bacterial communities may serve important roles in M. admirabilis health and survival in the anthropogenic environment. Overall, our results have important implications for the conservation and management of this microendemic and critically endangered species.
\end{abstract}

Keywords: high-throughput sequencing; amphibian; bacteria; xenobiotic; anthropogenic action 


\section{Introduction}

Amphibians are highly sensitive to environmental changes and represent the most threatened vertebrate group, with approximately 33\% (2390) of the 7166 known species listed in a threatened category [1-3]. The anuran genus Melanophryniscus (Bufonidae) comprises 29 species of small toads that are geographically restricted to South America, occurring in Brazil, Paraguay, Bolivia, Uruguay, and Argentina [4]. Many species have restricted distributions and are globally listed as threatened, near threatened [5], or data deficient [3]. Among the 22 species of Melanophryniscus found in Brazil, Melanophryniscus admirabilis (admirable red-belly toad) is a microendemic species found exclusively along $700 \mathrm{~m}$ of the Forqueta River in a fragment of the Atlantic Forest of southern Brazil [6]. M. admirabilis is one of the largest species in the genus (females grow up to $40 \mathrm{~mm}$, while males are smaller) [4]. They are easily distinguishable by their green dorsum with a black belly as well as contrasting yellowish glands and red palms, soles, and inguinal region [6]. Its conspicuous coloration-associated with unken reflex behavior-is supposedly a warning signal for potential predators that indicates toxicity due to their skin's alkaloid compounds. These alkaloids are sequestered from their arthropod-rich diet (e.g., ants, beetles, mites, and millipedes) and is released through their multicellular exocrine glands [7]. Approximately 170 alkaloids and 15 structural classes have already been identified in 9 species of Melanophryniscus [8], with 5,8-disubstituted indolizidines, 5,6,8-trisubstituted indolizidines, pumiliotoxins, tricyclics, and decahydroquinolines being the most commonly observed [9-11].

Melanophryniscus admirabilis is officially listed by International Union for Conservation of Nature (IUCN) as critically endangered and is part of the Action Plan for the Conservation of Amphibians and Reptiles in southern Brazil [6]. Notably, this species' main threats include the ongoing loss of habitat quality resulting from anthropogenic infrastructures and activities such as hydroelectric power generation, deforestation, pesticide use in tobacco and soybean plantations, livestock activity, the illegal pet trade, and trampling by tourists at reproductive sites [3]. Due to the vulnerability of the only known population of this species, the conservation of M. admirabilis is a priority in Brazil. The few studies involving this species largely focused on its biology, ecology [12], and ecotoxicology [13]. To date, no work has been carried out to examine the microbiota composition and/or diversity in this species. Notably, microbes serve an important role in maintaining animal health. Additionally, the adaptation and persistence of animal species in human-impacted environments have been associated with microbiota [2,14]. Determining microbiota composition could promote a greater understanding of species' physiological statuses and niche divergences under differing environmental conditions [15,16].

To date, amphibian skin and gut microbiomes have been relatively well studied; however, studies involving oral microbiome remain scarce [2,17-19]. The composition, diversity, and function of microbial communities mirrors host species' health maintenance in the environment and may also reflect the ecological condition of the habitat. The composition of microbiota in frogs is governed by the endogenous environment, shaped by their physical, physiological, and immune properties, and influenced by their surrounding environments via their diet, which constitutes an important source of organisms in the oral and gastrointestinal tracts of these animals. To ensure the successful conservation of $M$. admirabilis, it is important to assess the microbiota of this species. Therefore, the present study aimed to characterize the oral bacterial community of wild M. admirabilis and address the question of how this community might contribute to this species' adaptation in the anthropogenic environment as well as its general metabolic capabilities.

\section{Materials and Methods}

\subsection{Sample Collection}

Eleven oral samples were collected from wild Melanophryniscus admirabilis (Figure 1; Table 1). Samples were taken from active toads in the breeding sites in the Forqueta river's margins in the Perau de Janeiro locality, Arvorezinha, Rio Grande do Sul, Brazil (52 $18^{\prime} \mathrm{W}$, 
$28^{\circ} 51^{\prime} \mathrm{S}$ ). The area is situated at the southern end of the Atlantic Forest, in a transitional phytoecological region between the mixed ombrophilous forest and the deciduous seasonal forest [20].

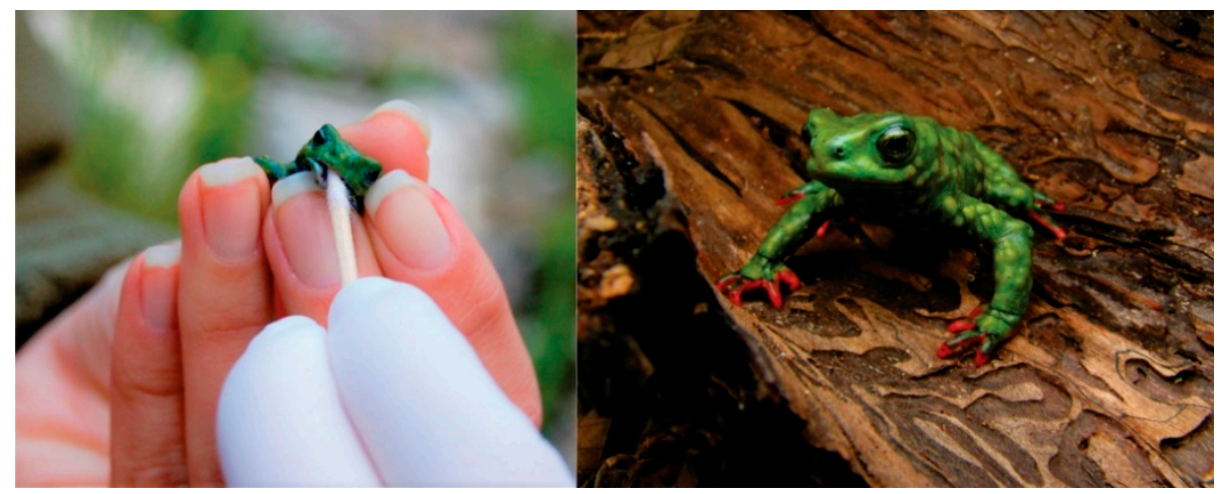

Figure 1. Wild Melanophryniscus admirabilis (admirable red-belly toads) in the Forqueta river's margins at the Perau de Janeiro Arvorezinha, South Brazil. Oral sample collected from the M. admirabilis (left; Photo: Márcio Borges-Martins). Melanophryniscus admirabilis in the breeding sites in the Forqueta river's margins at the Perau de Janeiro (right; Photo: Márcio Borges-Martins).

Table 1. Details of wild Melanophryniscus admirabilis (admirable red-belly toads) were analyzed in this study.

\begin{tabular}{cccc}
\hline SAMPLE $($ ID) & SVL ${ }^{*}(\mathbf{m m})$ & MASS $\mathbf{( g )}$ & SEX \\
\hline AC421 & 31.51 & 3.1 & Male \\
AC422 & 29.88 & 3 & Male \\
AC423 & 30.63 & 3.2 & Male \\
TA01 I & 35.46 & 3.6 & Female \\
TA02 II & 33.62 & 3.2 & Male \\
TA04 IV & 31.50 & 2.7 & Male \\
TA05 & 34.72 & 3.8 & Female \\
TA07 VII & 32.33 & 3.6 & Male \\
TA10 X & 33.87 & 4.2 & Female \\
TA11 XI & 33.67 & 4.1 & Male \\
TA12 XII & 35.07 & 3.9 & Male \\
\hline *SVL-Snout-vent length & & &
\end{tabular}

ॠSVL-Snout-vent length.

The oral swab collection was performed according to the sample collection protocol [21]. Oral samples were collected using commercially available sterile cotton-tipped swab sticks. All samples were placed in sterile tubes, kept on ice, and sent to our laboratory for storage at $-80{ }^{\circ} \mathrm{C}$. The toads were released back into the wild immediately after the sample collection. All specimens were individually marked using a photo identification protocol [12].

\subsection{Ethics and Sampling Permits}

This study was carried out following the recommendations of the Chico Mendes Institute for Biodiversity Conservation (ICMBio) and was approved by the Research and Ethics Committees at the Federal University of Rio Grande do Sul (Projects 19541, 25526, and 25528). The protocol was approved by the Information and Authorization System in Biodiversity (SISBIO), numbers 40004-5 and 10341-1 (for M. Borges-Martins). All possible measures were taken to reduce the impact of our sampling protocol, which is part of a larger program intended for the study, monitoring, and conservation of the only known admirable red-belly toad population. Research priorities and protocols are also part of the Action Plan for the Conservation of Amphibians and Reptiles in southern Brazil [12]. 


\subsection{DNA Extraction, PCR-Amplification of Bacterial $16 S$ rRNA Genes and Sequencing}

Total DNA from the oral swab samples was extracted using a DNeasy Blood and Tissue Kit (Qiagen, Valencia, CA, USA), according to the manufacturer's instructions. The DNA concentration was determined using the Qubit, and DNA quality was verified using the NanoDrop ND-1000 (Thermo Fisher Scientific, Waltham, MA, USA).

To characterize the bacterial community present in each oral sample, fragments of the $16 S$ rRNA gene were amplified using the primers 515F and 806R [22]. Multiple samples were PCR-amplified using barcoded primers linked with the Ion adapter " $\mathrm{A}$ " sequence and the Ion adapter " $\mathrm{P} 1$ " sequence to obtain a sequence of primer composed for A-barcode-806R and P1-515F adapter and primers. PCR reactions were carried out with the Platinum Taq DNA Polymerase High Fidelity kit (Invitrogen, Carlsbad, CA, USA). PCR was performed with High Fidelity PCR buffer, $2 \mathrm{U}$ of Platinum Taq DNA Polymerase, $2 \mathrm{mM}$ of $\mathrm{MgSO}_{4}$, $0.2 \mathrm{mM}$ of dNTP Mix, $25 \mu \mathrm{g}$ of Ultrapure BSA (Invitrogen, Carlsbad, CA, USA), $0.1 \mu \mathrm{M}$ of each forward primer, approximately $30 \mathrm{ng}$ of DNA template, and ultrapure water to complete a final volume of $25 \mu \mathrm{L}$ per reaction. The PCR conditions were $94^{\circ} \mathrm{C}$ for $5 \mathrm{~min}$, followed by 30 cycles of $94{ }^{\circ} \mathrm{C}$ for $45 \mathrm{~s}, 56^{\circ} \mathrm{C}$ for $45 \mathrm{~s}$, and $68^{\circ} \mathrm{C}$ for $1 \mathrm{~min}$, and a final extension step of $68^{\circ} \mathrm{C}$ for $10 \mathrm{~min}$.

Samples were sequenced at the Universidade Federal do Pampa (UNIPAMPA, Bagé, RS, Brazil). After purifying PCR amplicons using Agencount AMPure Beads (Beckman Coulter), library preparation was carried out with the Ion OneTouch ${ }^{\mathrm{TM}} 2$ System fitted with the Ion PGMTM OT2 400 Kit Template (Thermo Fisher Scientific, Waltham, MA, USA) from an initial amount of $100 \mathrm{ng}$ of PCR product. Because all samples were sequenced in a multiplexed Personal Genome Machine (PGM) run, barcode sequences were used to identify each sample from the total sequencing output. Sequencing was conducted on an Ion Personal Genome Machine (PGM) System (Thermo Fisher Scientific, Waltham, MA, USA) with 316 chips, following the manufacturer's instructions. Sequences have been submitted to the European Molecular Biology Laboratory (EMBL) database under accession number PRJEB33232. Despite the short-read lengths ( $290 \mathrm{bp})$, this targeted gene region should also provide sufficient resolution.

\subsection{Bacterial Community Analysis}

Bioinformatics analysis of $16 \mathrm{~S} r$ RNA amplicons was performed using QIIME 2 version 2019.7 [22]. Raw sequence data were quality filtered, denoised, and chimera filtered using the q2-dada2- plugin with DADA2 pipeline Callahan [23]. The $5^{\prime}$ and $3^{\prime}$ nucleotide bases were trimmed from forward and reverse read sequences due to low quality. Reads with several expected errors higher than 4 were discarded. Read length filtering was applied, and the reads were trimmed at the first instance of a quality score less than or equal to 2. The resulting reads were truncated at $200 \mathrm{bp}$ length. Chimera removal was performed using the consensus method. The amplicon sequence variants (ASVs) obtained by DADA2 pipeline were merged into a single feature table using the q2-feature-table plugin.

The ASV's were aligned with multiple alignment using fast Fourier transform (MAFFT) (via q2-alignment) [24]. Taxonomy was assigned to the classify-sklearn naive Bayes taxonomy classifier [25]. The classifier was trained using extracted Greengenes 13_8 reference sequences with $99 \%$ similarity from $16 S$ rRNA variable region 4 (V4). The resulting feature table, rooted tree from reconstructed phylogeny, and taxonomy classification were imported from QIIME2 to the R v3.6.1 environment for further data analysis using Microbiome v1.6.0 and Phyloseq v1.28.0 [26,27]. For Taxonomic analysis, the feature table was transformed to compositional data for taxa bar plot composition visualization of the five most abundant phylum and families using the plot composition function from Microbiome $R$ package [27].

The taxon diversity study (richness and evenness) within the samples was performed by employing the Shannon diversity, the InvSimpson diversity, and the Chao1 index, whereas the observed species metrics calculation and diversity between samples were estimated using Microbiome and Phyloseq packages in R. The significance was estimated 
with a pairwise comparison using a non-parametric test Wilcoxon [28], using functions from the Microbiome R package.

\subsection{Functional Predictions from Amplicon Sequences}

A predictive functional profile of the oral bacterial community was conducted using PICRUSt2 software [29] against Kyoto Encyclopedia of Genes and Genomes (KEGG) database [30]. PICRUSt2 output is a biom table with rows in terms of functional orthologs $(\mathrm{KO})$ and samples as columns. The KO terms levels were mapped into KEGG levels and imported to statistical analysis of taxonomic and functional profiles (STAMP) software for statistical analysis [31]. Briefly, samples were divided into two gender groups (F-M), and a Welch's $t$-test was performed to evaluate the significance of functional predictions with $p$-value $<0.05$. Benjamini-Hochberg adjusted $p$-value was calculated to control the false discovery rate (FDR) in multiple testing. The KEGG groups were considered significantly enriched by satisfying an FDR corrected $p$-value of 0.05 .

\section{Results}

A total of 181,350 sequences were obtained from the oral samples of wild Melanophryniscus admirabilis after discarding substandard sequences. Among these cleaned sequences, we obtained 13,650 ASVs per sample, which were grouped into 1039 (ASVs). Sequence analysis grouped the reads into 16 phyla, 34 classes, 39 orders, and 77 families.

Five phyla presented relative abundances greater than $1 \%$ and were present in all evaluated samples. Among phyla, Proteobacteria dominated the oral microbiota of wild M. admirabilis, with the highest relative abundance (53\%), followed by Firmicutes (18\%), Bacteroidetes (17\%), Actinobacteria (5\%), and Fusobacteria (2\%) (Figure 2; Table S1). These sequences belonged mainly to seven orders: Burkholderiales (23\%), Bacteroidales (14\%), Lactobacillales (8\%), Clostridiales (8\%), Enterobacteriales (7\%) Pseudomonadales (5\%), and Actinomycetales (5\%) (Table S2).

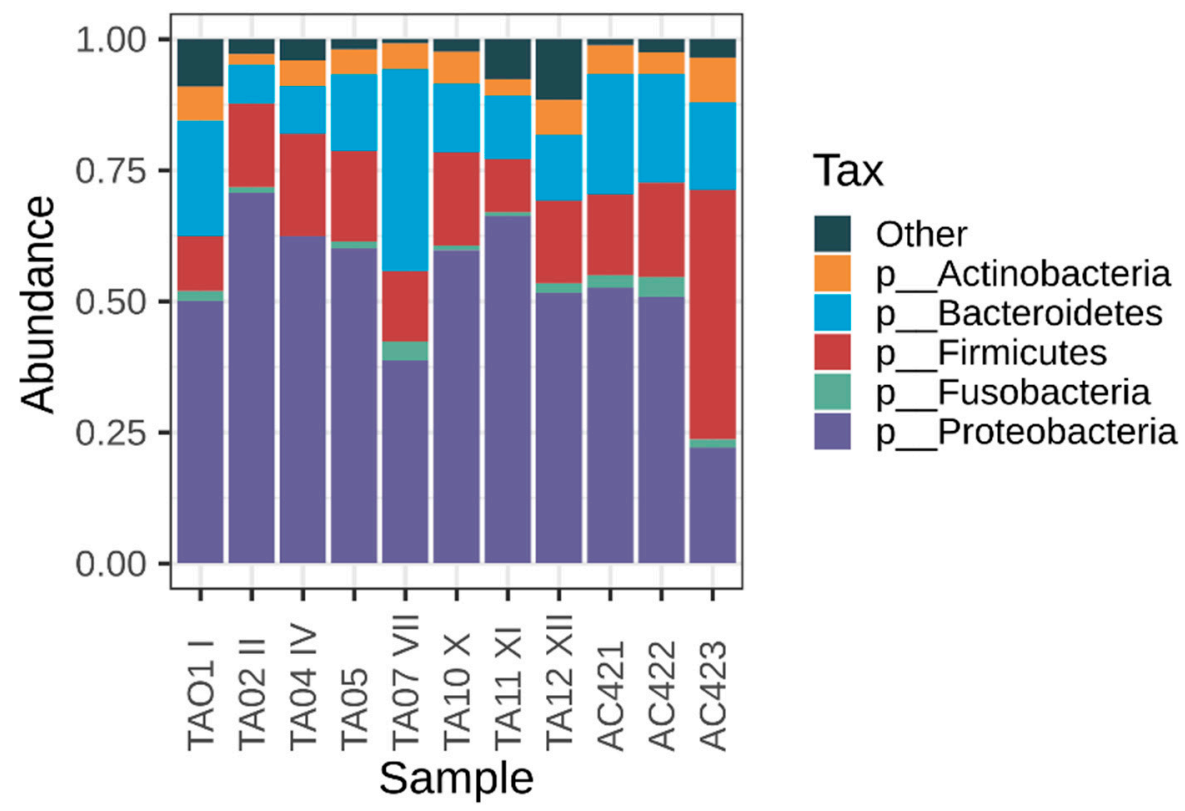

Figure 2. Oral bacterial composition of wild Melanophryniscus admirabilis (admirable red-belly toads). Taxonomic composition of the oral microbiota among the eleven samples was compared based on the relative abundance (reads of a taxon/total reads in a sample).

While 77 families were detected in the oral samples, only 28 families exhibited a relative average abundance of $\geq 1 \%$ (Table S3). Burkholderiaceae (16\%), Prevotellaceae $(10 \%)$, Enterobacteriaceae $(7 \%)$, Comamonadaceae $(6 \%)$, and Streptococcaceae $(6 \%)$ were more abundant and were present in all samples evaluated (Figure S1). 
Alpha diversity metrics (Shannon, Chao1, Inverse Simpson index) did not exhibit any identifiable change ( $p$-value $>0.05)$ in bacterial community structure grouping samples by sex (Figure 3).

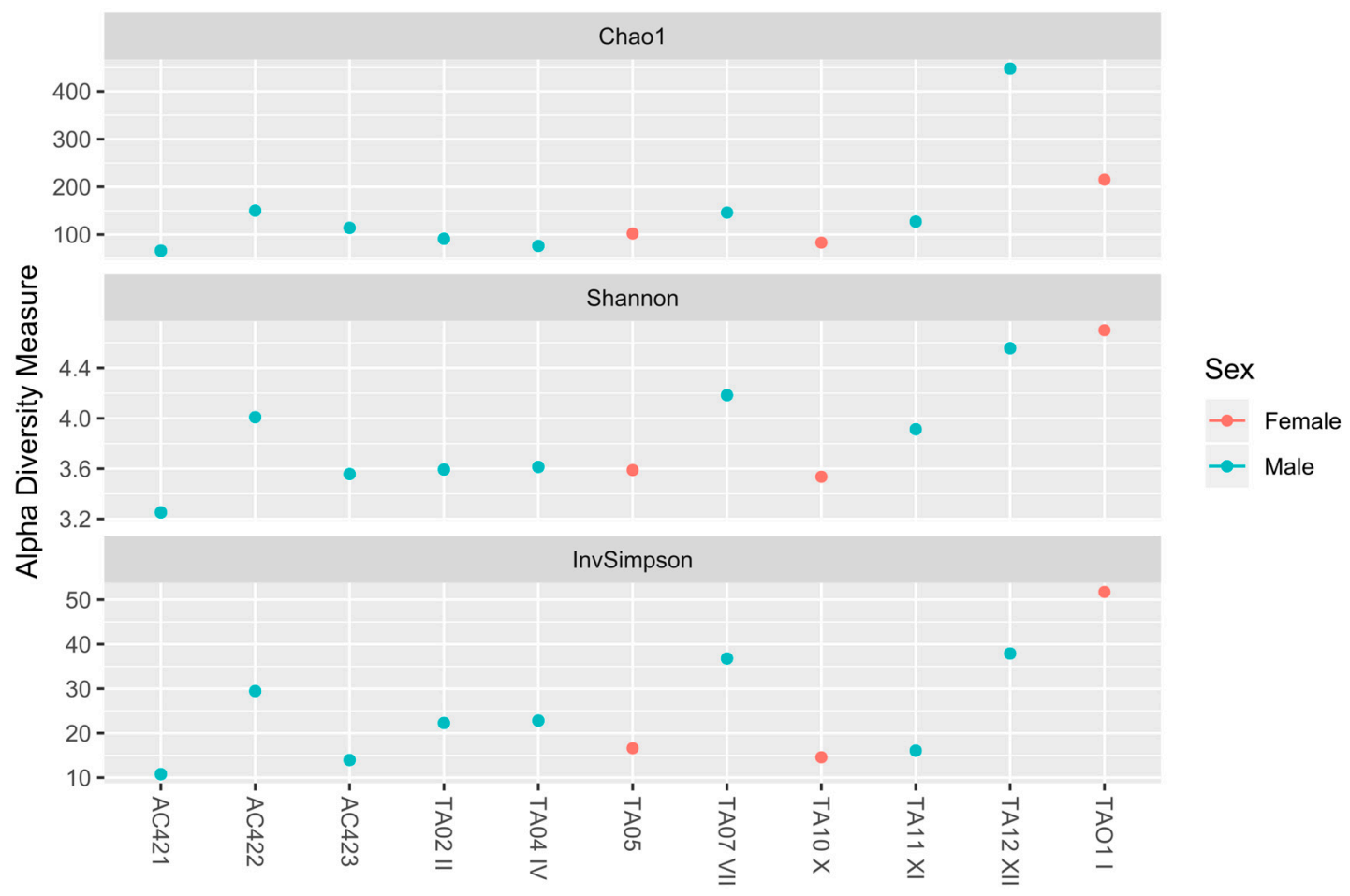

Figure 3. Alpha diversity comparisons of oral bacterial microbiota of wild Melanophryniscus admirabilis (admirable red-belly toads). Alpha-diversity analysis based on Chao 1 diversity (top), Shannon diversity (middle), and InvSimpson diversity (bottom), measure of species richness based on amplicon sequence variants (ASVs) of the eleven oral samples collected from wild M. admirabilis. No significant difference among the samples was observed.

PICRUSt2 software was used to better understand the important role of the oral bacterial microbiota present in wild M. admirabilis. Metabolic functions were enriched in our samples, and functional features in 26 pathways were observed, including membrane transport proteins, amino acids metabolism, carbohydrate metabolism, energy metabolism, replication and repair systems, cofactor and vitamin metabolism, nucleotide metabolism, xenobiotic biodegradation metabolism, lipid metabolism, the metabolism of other amino acids, polypeptide and terpenoid metabolism, and the biosynthesis of other secondary metabolites (Figure S2).

We correlated the microbial functional features (e.g., xenobiotic degradation and metabolism) with toad habitat and diet. A total of 16 pathways were identified using PICRUSt2 software (Figure 4; Table S4). Two of these pathways were related to benzoate and toluene degradation, with an elevated frequency of amplicon sequence variants (average number of ASVs = 54,486 and 36,950, respectively). The data analysis showed a higher standard deviation for benzoate degradation and toluene degradation when compared to polycyclic aromatic hydrocarbon degradation (Table S4). Other groups of xenobiotic activity included aminobenzoate degradation (average number of ASVs $=30,067$ ), chloroalkane and chloroalkene degradation (average number of ASVs = 25,160), drug metabolismcytochrome P450 (average number of ASVs $=19,923$ ), naphthalene degradation (average number of ASVs = 19,789), nitrotoluene degradation (average number of ASVs = 12,598), ethylbenzene degradation (average number of ASVs $=9718$ ), dioxin degradation and biosynthesis (average number of ASVs $=6847$ ), atrazine degradation (average number of ASVs $=5576)$, and fluorobenzoate degradation (average number of ASVs $=5864)($ Table S4). 


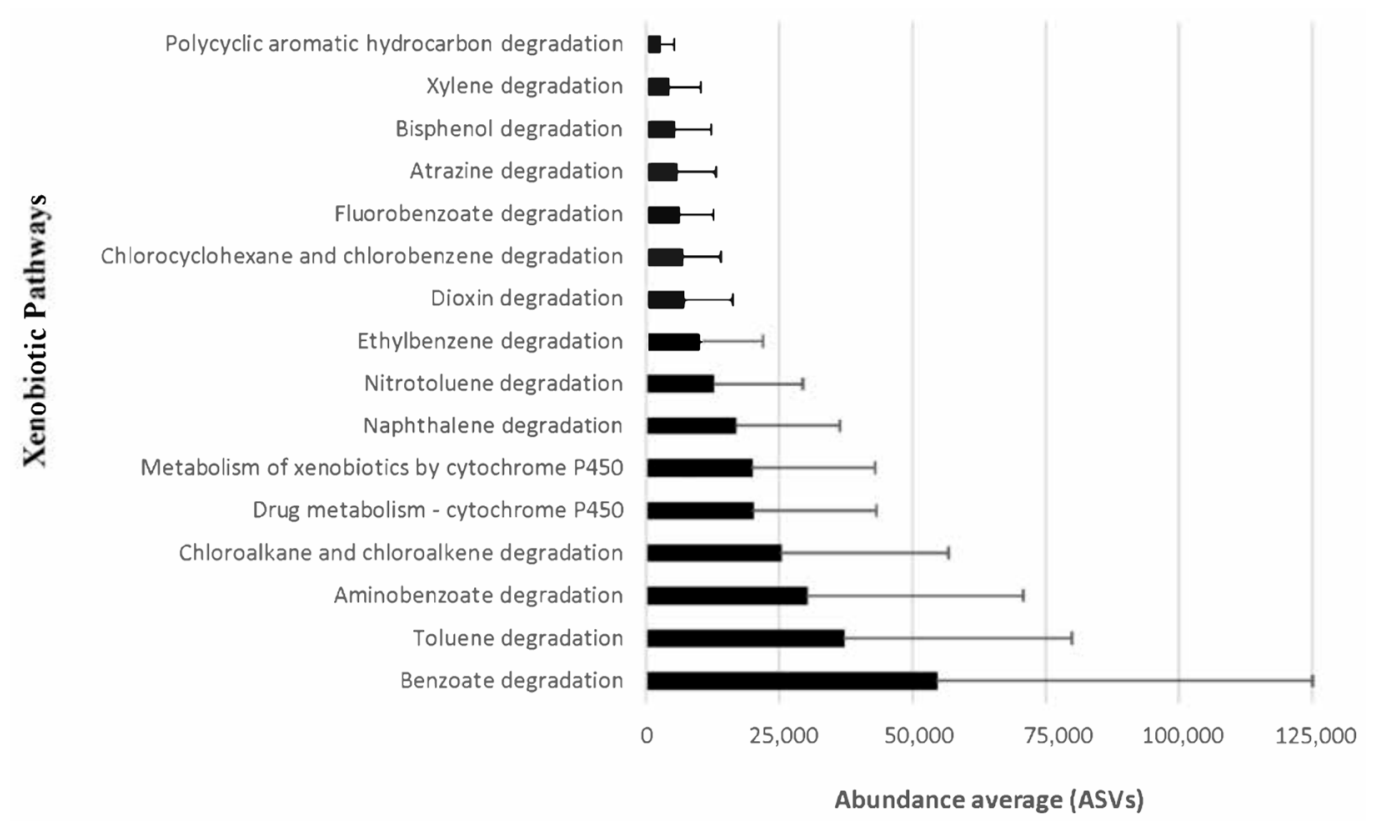

Figure 4. Average number of amplicon sequence variants (ASVs) $>1 \%$ average relative abundance) among the $16 S$ rRNA gene profiles of oral samples from wild Melanophryniscus admirabilis belonging to the predicted xenobiotic pathways in relative Kyoto Encyclopedia of Genes and Genomes (KEEG) Level 2.

\section{Discussion}

The number of amphibian microbiome studies has been increasing in recent years to facilitate an improved understanding of the diverse communities of bacteria, fungi, and viruses that inhabit their bodies [2,17-19,32,33]. The skin microbiome has been extensively studied due to its relationship to an emergent disease caused by the chytrid fungus (Batrachochytrium dendrobatidis) [2,32]. However, knowledge regarding the taxonomic content of amphibian oral microbiota remains extremely limited [2,17-19]. In the present study, we describe the bacterial communities present in the oral cavity of wild Melanophryniscus admirabilis with the use of high-throughput sequencing for the first time

Proteobacteria, Firmicutes, Bacteroidetes, Actinobacteria, and Fusobacteria (which accounted for $95 \%$ of the oral microbial community composition), represent typical mucosal taxa and were shared among all samples. These microbial phyla have been associated with symbiotic roles and are commonly observed in the amphibian gastrointestinal tract [34-36]. Chang et al. [33] reported that Bacteroides, Firmicutes, and Proteobacteria were also dominant among the intestinal microbiota of rice frogs (Fejervarya limnocharis) in natural and farmland habitats. Moreover, according to a study performed in Canada and the United States, over $75 \%$ of the gut microbial composition of Rana pipiens (northern leopard frogs) included Proteobacteria and Firmicutes [37].

In oral samples of wild M. admirabilis, Proteobacteria represented $53 \%$ of the assigned sequence variants. Notably, the diet route constitutes an important source of organisms in the oral and gastrointestinal tract of these animals. The presence of Proteobacteria in oral samples may be associated with the diet of this species being arthropod-rich because this phylum was observed as dominant in the cuticular microbiomes of ants and the gut microbiomes of arthropods [38]. However, the predominance of this phylum may also be associated with the ability of M. admirabilis to synthesize bioactive secondary metabolites that are frequently observed in several bacteria of this phylum [39]. For example, Janthinobacterium lividum was present in amphibian guts and inhibited the growth of lethal amphibian fungus [40]. Additionally, antifungal activity from the genus Pseudomonas was discovered on the skin of Rana muscosa (mountain yellow-legged frogs) and R. pipiens $[41,42]$. In this sense, the oral microbiota of amphibians should be investigated further 
because it may be a source of compounds with antimicrobial activity that affects their associated microbial community diversity or composition.

The oral cavity of wild M. admirabilis was dominated by the orders Burkholderiales (Burkholderiaceae and Comamonadaceae), Enterobacteriales (Enterobacteriaceae), and Bacteroidales (Prevotellaceae). Some microorganisms belonging to these orders coexist with frogs in their habitat. For example, Burkholderiales was found in the skins of terrestrial (Rhinella marina, Litoria nasuta, and Limnodynases convexiusculus) and arboreal (L. caerulea, L. rubella, and L. rothii) anuran species [43]. Furthermore, Burkholderiaceae and Comamonadaceae family members have diverse ecological niches and are found in soil, animals, fungi, and water associated with plants [44,45]. Moreover, Bacteroidales have been reported as symbiotic bacteria essential to the digestive activity of several organisms [40].

In the present study, we observed a similar composition among microbial communities in all oral samples. Recently, Chang et al. [33] hypothesized that the composition of gut microbiota from frogs should be governed by the endogenous gut environment, which is shaped by the physical, physiological, and immune properties of host species, and would be less influenced by the surrounding environment. Here, we suggest that the similarity observed across the oral bacteria communities present in M. admirabilis might also be governed by the endogenous oral environment (e.g., saliva [46] and the surrounding environment) because this frog species is microendemic and has a low dietary diversity consisting of arthropods (e.g., Formicidae, Acari, and Coleoptera) that live in this environment [47].

Based on metagenome predictions, one of the most striking observations was xenobiotic degradation in the bacterial community. The communities of bacteria associated with this pathway could suggest positive effects on toad health among populations facing anthropogenic pollutants. Melanophryniscus admirabilis belongs to a threatened class of vertebrates, and its observed population decline is due to a combination of different factors, including habitat degradation and fragmentation due to agriculture as well as exposure to contaminants stemming from these activities [12]. Nutrient enrichment from agricultural pollution may reshape the structure of the microbiome composition of aquatic animals and increase their vulnerability to disease [2]. One study analyzed possible alterations to the metabolic and oxidative parameters of total homogenate in M. admirabilis tadpoles exposed to two concentrations of commercial formulations containing sulfentrazone (Boral ${ }^{\circledR} 500 \mathrm{SC}$ ) and two concentrations containing glyphosate (Roundup ${ }^{\circledR}$ Original). Significant alterations in metabolic and oxidative parameters were observed in groups exposed to sulfentrazone and glyphosate herbicides. However, the tadpoles of this species are capable of moderating potential oxidative lipid damage [13]. Thus, in light of the results of the present study, we suggest that the associated mobilization of enzymes and a microbial community capable of degrading xenobiotics should have a positive effect on the persistence of M. admirabilis in this human-impacted environment. Notably, additional factors such as habitat fragmentation, UV radiation, and exposure to other pollutants have negative effects that can interact to affect the survival of these animals. Environmental contaminants such as xenobiotics can alter host-associated microbial communities through the displacement of native bacterial taxa by those capable of withstanding chronic exposure to toxic compounds [48]. Ultimately, improving our knowledge of amphibian microbiomes is important to numerous fields, including species conservation, the detection and quantification of environmental changes and stressors, and the discovery of new compounds with medical applications.

\section{Conclusions}

Amphibians are important components of most ecosystems and serve a critical role in many food webs, especially in highly diverse tropical areas. Melanophryniscus admirabilis is a critically endangered and microendemic species whose survival is directly related to our ability to understand its ecology, identify major anthropic impacts, and act to preserve its habitat. This work advances current knowledges of the oral microbiota of this species. Our data support the predominance of the phylum Proteobacteria in the oral microbiota 
of M. admirabilis. No significant differences among the microbial community profile from different samples were reported, suggesting that low diet diversity in this population may directly influence the bacterial composition. Oral microbiota contributed to a range of metabolic pathways, with membrane transport, amino acid metabolism, carbohydrate metabolism, replication, and repair predicted as the most prominent categories. The results of this study highlight the potential functional profiles of the xenobiotic degradation pathway in the oral microbiota of these toads. These communities might serve important roles in the health and survival of this species while also serving as an essential component of a successful conservation strategy. Therefore, our results contribute to the knowledge of ecological aspects of M. admirabilis's oral microbiota, which may have important implications for the conservation and management of this critically endangered species because it occurs in a narrow range of environmental conditions and is experiencing an ongoing reduction in habitat quality.

Supplementary Materials: The following are available online at https:/ /www.mdpi.com/2076-260 7/9/2/220/s1: Table S1, Percentage and average of identified phyla (>1\%) among the eleven oral samples of wild Melanophryniscus admirabilis (admirable red-belly toads); Table S2, Percentage and average of identified order ( $>1 \%)$ among the eleven oral samples of wild Melanophryniscus admirabilis (admirable red-belly toads); Table S3, Percentage and average of identified family $(>1 \%)$ among the eleven oral samples of wild Melanophryniscus admirabilis (admirable red-belly toads); Table S4, Relative abundance of amplicon sequence variants belonging to the persistent groups in relative KEGG Level 2 of xenobiotic/drug metabolism identified among the eleven oral samples of wild Melanophryniscus admirabilis (admirable red-belly toads); Figure S1, Five most abundant families presented in the eleven oral samples of wild Melanophryniscus admirabilis (admirable red-belly toads). Taxonomic composition of the oral microbiota among the eleven samples was compared based on the relative abundance (reads of a taxon/total reads in a sample); Figure S2., Heatmap of the significant predicted KEGG pathways from the oral bacterial community of the eleven wild Melanophryniscus admirabilis (admirable red-belly toads).

Author Contributions: Conceptualization, M.B.M., J.P., M.A., T.M.D.F.L., and V.C.; data curation, M.B.M., I.M.S.d.C., and J.M.S.; formal analysis, M.B.M., J.P., M.B.-M., J.F., and A.P.G.F.; funding acquisition, J.F. and A.P.G.F.; methodology, M.B.M., M.A., T.M.D.F.L., and V.C.; software, J.P., I.M.S.d.C., and J.M.S.; supervision, M.B.-M., J.F., and A.P.G.F.; writing-original draft, M.B.M. and J.P.; Writingreview and editing, M.B.-M., J.F., and A.P.G.F. All authors have read and agreed to the published version of the manuscript.

Funding: We are grateful to the Brazilian Microbiome Project (BMP) that supported this work. We thank the Conselho Nacional de Desenvolvimento Científico e Tecnológico do Brasil (CNPq\#302574/2017-0, \#407886/2018-4, and \#305495/2018-6) and the Coordenação de Aperfeiçoamento de Pessoal de Nível Superior (CAPES) of the Brazilian government.

Institutional Review Board Statement: This study was conducted according to the guidelines of the Chico Mendes Institute for Biodiversity Conservation (ICMBio) and approved by the Research and Ethics Committee at the Federal University of Rio Grande do Sul (protocol code 25526 at 09/09/2013). The protocol was approved by the Information and Authorization System in Biodiversity (SISBIO), numbers 40004-5 and 10341-1 (for Borges-Martins, M).

Informed Consent Statement: Not applicable.

Data Availability Statement: The data presented in this study are openly available in European Molecular Biology Laboratory (EMBL) accession codes PRJEB33232.

Acknowledgments: We thank the Fundação Grupo Boticário, Mohamed Bin Zayed Species Conservation Fund, Centro Nacional de Pesquisa e Conservação de Répteis e Anfíbios (RAN/ICMBio) and the Instituto Curicaca for logistic support. We are also grateful to Aline Weber Medeiros, Fabricio de Souza Campos, and MSc. Rosana Huff for their contributions to this work.

Conflicts of Interest: The authors declare no conflict of interest. 


\section{References}

1. Frost, D.R. Amphibian Species of the World: An Online Reference. Version 6.1. Available online: https://amphibiansoftheworld. amnh.org/index.php (accessed on 8 January 2021).

2. Preuss, J.F.; Greenspan, S.E.; Rossi, E.M.; Gonsales, E.M.L.; Neely, W.J.; Valiati, V.H.; Woodhams, D.C.; Becker, C.G.; Tozetti, A.M. Widespread pig farming practice linked to shifts in skin microbiomes and disease in pond-breeding amphibians. Environ. Sci. Technol. 2020, 54, 11301-11312. [CrossRef]

3. IUCN 2020. The IUCN Red List of Threatened Species. Version 2020-3. Available online: https://www.iucnredlist.org (accessed on 8 January 2021).

4. Zank, C.; Becker, F.G.; Abadie, M.; Baldo, D.; Maneyro, R.; Borges-Martins, M. Climate change and the distribution of neotropical red-bellied toads (Melanophryniscus, Anura, Amphibia): How to prioritize species and populations? PLoS ONE 2014, 9 , e94625. [CrossRef] [PubMed]

5. Bordignon, D.W.; Caorsi, V.Z.; Colombo, P.; Abadie, M.; Brack, I.V.; Dasoler, B.T.; Borges-Martins, M. Are the unken reflex and the aposematic colouration of Red-Bellied Toads efficient against bird predation? PLoS ONE 2018, 13, e0193551. [CrossRef]

6. Di-Bernardo, M.; Maneyro, R.; Grillo, H. New species of Melanophryniscus (Anura: Bufonidae) from Rio Grande do Sul, Southern Brazil. South Am. J. Herpetol. 2006, 40, 261-266. [CrossRef]

7. Daly, J.W.; Highet, R.J.; Myers, C.W. Occurrence of skin alkaloids in non-dendrobatid frogs from Brazil (Bufonidae), Australia (Myobatrachidae) and Madagascar (Mantellinae). Toxicon 1984, 22, 905-919. [CrossRef]

8. Garraffo, H.M.; Andriamaharavo, N.R.; Vaira, M.; Quiroga, M.F.; Heit, C.; Spande, T.F. Alkaloids from single skins of the Argentinian toad Melanophryniscus rubriventris (ANURA, BUFONIDAE): An unexpected variability in alkaloid profiles and a profusion of new structures. SpringerPlus 2012, 1, 1-15. [CrossRef] [PubMed]

9. Daly, J.W.; Spande, T.F.; Garraffo, H.M. Alkaloids from amphibian skin: A tabulation of over eight-hundred compounds. J. Nat. Prod. 2005, 68, 1556-1575. [CrossRef]

10. Hantak, M.M.; Grant, T.; Reinsch, S.; McGinnity, D.; Loring, M.; Toyooka, N.; Saporito, R.A. Dietary alkaloid sequestration in a poison frog: An experimental test of alkaloid uptake in Melanophryniscus stelzneri (Bufonidae). J. Chem. Ecol. 2013, 39, 1400-1406. [CrossRef]

11. Saporito, R.A.; Donnelly, M.A.; Spande, T.F.; Garraffo, H.M. A review of chemical ecology in poison frogs. Chemoecology 2012, 22, 159-168. [CrossRef]

12. Fonte, L.; Abadie, M.; Mendes, T.; Zank, C.; Borges-Martins, M. The times they are a-changing: How a multi-institutional effort stopped the construction of a hydroelectric power plant that threatened a critically endangered red-belly toad in Southern Brazil. FrogLog 2014, 22, 18-21.

13. Da Silva, P.R.; Borges-Martins, M.; Oliveira, G.T. Melanophryniscus admirabilis tadpoles' responses to sulfentrazone and glyphosatebased herbicides: An approach on metabolism and antioxidant defenses. Environ. Sci. Pollut. Res. 2020, 1-17. [CrossRef] [PubMed]

14. Karl, J.P.; Hatch, A.M.; Arcidiacono, S.M.; Pearce, S.C.; Pantoja-Feliciano, I.G.; Doherty, L.A.; Soares, J.W. effects of psychological, environmental and physical stressors on the gut microbiota. Front. Microbiol. 2018, 9, 2013. [CrossRef] [PubMed]

15. Stevenson, T.J.; Duddleston, K.N.; Buck, C.L. Effects of season and host physiological state on the diversity, density, and activity of the arctic ground squirrel cecal microbiota. Appl. Environ. Microbiol. 2014, 80, 5611-5622. [CrossRef] [PubMed]

16. Bolaños, L.M.; Rosenblueth, M.; Castillo-Ramírez, S.; Figuier-Huttin, G.; Martínez-Romero, E. Species-specific diversity of novel bacterial lineages and differential abundance of predicted pathways for toxic compound degradation in scorpion gut microbiota. Environ. Microbiol. 2016, 18, 1364-1378. [CrossRef]

17. Shu, Y.; Hong, P.; Tang, D.; Qing, H.; Donde, O.O.; Wang, H.; Xiao, B.; Shu, Y. Comparison of intestinal microbes in female and male Chinese concave-eared frogs (Odorrana tormota) and effect of nematode infection on gut bacterial communities. Microbiologyopen 2019, 8, e00749. [CrossRef]

18. Kueneman, J.G.; Weiss, S.; McKenzie, V.J. Composition of micro-eukaryotes on the skin of the cascades frog (Rana cascadae) and patterns of correlation between skin microbes and Batrachochytrium dendrobatidis. Front. Microbiol. 2017, 8, 2350. [CrossRef]

19. Jiménez, R.R.; Sommer, S. The amphibian microbiome: Natural range of variation, pathogenic dysbiosis, and role in conservation. Biodivers. Conserv. 2017, 26, 763-786. [CrossRef]

20. Machado, A.B.M.; Drummond, G.M.; Paglia, A.P. Livro Vermelho da Fauna Brasileira Ameaçada de Extinção; MMA: Brasília, Brazil, 2008.

21. Schulte, U.; Gebhard, F.; Heinz, L.; Veith, M.; Hochkirch, A. Buccal swabs as a reliable non-invasive tissue sampling method for DNA analysis in the lacertid lizard Podarcis muralis. North. West. J. Zool. 2011, 7, 325-328.

22. Caporaso, J.G.; Lauber, C.L.; Walters, W.A.; Berg-Lyons, D.; Huntley, J.; Fierer, N.; Owens, S.M.; Betley, J.; Fraser, L.; Bauer, M.; et al. Ultra-high-throughput microbial community analysis on the Illumina HiSeq and MiSeq platforms. ISME J. 2012, 6, $1621-1624$. [CrossRef]

23. Callahan, B.J.; McMurdie, P.J.; Rosen, M.J.; Han, A.W.; Johnson, A.J.A.; Holmes, S.P. DADA2: High-resolution sample inference from Illumina amplicon data. Nat. Methods 2016, 13, 581-583. [CrossRef]

24. Katoh, K.; Misawa, K.I.; Kuma, K.; Miyata, T. MAFFT: A novel method for rapid multiple sequence alignment based on fast Fourier transform. Nucleic Acids Res. 2002, 30, 3059-3066. [CrossRef] [PubMed] 
25. Bokulich, N.A.; Kaehler, B.D.; Rideout, J.R.; Dillon, M.; Bolyen, E.; Knight, R.; Huttley, G.; Caporaso, J.G. Optimizing taxonomic classification of marker-gene amplicon sequences with QIIME 2's q2-feature-classifier plugin. Microbiome 2018, 6, 1-17. [CrossRef] [PubMed]

26. McMurdie, P.J.; Holmes, S. phyloseq: An R Package for reproducible interactive analysis and graphics of microbiome census data. PLoS ONE 2013, 8, e61217. [CrossRef] [PubMed]

27. Lahti, L.; Shetty, S.; Blake, T.; Salojarvi, J. Microbiome: Tools for Microbiome Analysis in r. 2017. Available online: http:/ / microbiome. github.com/microbiome (accessed on 8 January 2021).

28. Wilcoxon, F. Individual Comparisons by Ranking Methods. Biom. Bull. 1945, 1, 80. [CrossRef]

29. Douglas, G.M.; Maffei, V.J.; Zaneveld, J.; Yurgel, S.N.; Brown, J.R.; Taylor, C.M.; Huttenhower, C.; Langille, M.G.I. PICRUSt2: An improved and customizable approach for metagenome inference. BioRxiv 2020. [CrossRef]

30. Kanehisa, M.; Sato, Y.; Kawashima, M.; Furumichi, M.; Tanabe, M. KEGG as a reference resource for gene and protein annotation. Nucleic Acids Res. 2016, 44, D457-D462. [CrossRef]

31. Parks, D.H.; Tyson, G.W.; Hugenholtz, P.; Beiko, R.G. STAMP: Statistical analysis of taxonomic and functional profiles. Bioinformatic 2014, 30, 3123-3124. [CrossRef]

32. Kueneman, J.G.; Bletz, M.C.; McKenzie, V.J.; Becker, C.G.; Joseph, M.B.; Abarca, J.G.; Archer, H.; Arellano, A.L.; Bataille, A.; Becker, M.; et al. Community richness of amphibian skin bacteria correlates with bioclimate at the global scale. Nat. Ecol. Evol. 2019, 3, 381-389. [CrossRef]

33. Chang, C.-W.; Huang, B.-H.; Lin, S.-M.; Huang, C.-L.; Liao, P.-C. Changes of diet and dominant intestinal microbes in farmland frogs. BMC Microbiol. 2016, 16, 33. [CrossRef]

34. Scheele, B.C.; Pasmans, F.; Skerratt, L.F.; Berger, L.; Martel, A.; Beukema, W.; Acevedo, A.A.; Burrowes, P.A.; Carvalho, T.; Catenazzi, A.; et al. Amphibian fungal panzootic causes catastrophic and ongoing loss of biodiversity. Science 2019, 363, 1459-1463. [CrossRef]

35. Bletz, M.C.; Goedbloed, D.J.; Sanchez, E.; Reinhardt, T.; Tebbe, C.C.; Bhuju, S.; Geffers, R.; Jarek, M.; Vences, M.; Steinfartz, S. Amphibian gut microbiota shifts differentially in community structure but converges on habitat-specific predicted functions. Nat. Commun. 2016, 7, 13699. [CrossRef] [PubMed]

36. Huang, B.-H.; Chang, C.-W.; Huang, C.-W.; Gao, J.; Liao, P.-C. Composition and functional specialists of the gut microbiota of frogs reflect habitat differences and agricultural activity. Front. Microbiol. 2018, 8, 2670. [CrossRef] [PubMed]

37. Kohl, K.D.; Cary, T.L.; Karasov, W.H.; Dearing, M.D. Restructuring of the amphibian gut microbiota through metamorphosis. Environ. Microbiol. Rep. 2013, 5, 899-903. [CrossRef] [PubMed]

38. Yun, J.-H.; Roh, S.W.; Whon, T.W.; Jung, M.-J.; Kim, M.-S.; Park, D.-S.; Yoon, C.; Nam, Y.-D.; Kim, Y.-J.; Choi, J.-H.; et al. Insect gut bacterial diversity determined by environmental habitat, diet, developmental stage, and phylogeny of host. Appl. Environ. Microbiol. 2014, 80, 5254-5264. [CrossRef]

39. Itävaara, M.; Salavirta, H.; Marjamaa, K.; Ruskeeniemi, T. Geomicrobiology and metagenomics of terrestrial deep subsurface microbiomes. Adv. Clin. Chem. 2016, 94, 1-77. [CrossRef]

40. Ramsey, J.P.; Mercurio, A.; Holland, J.A.; Harris, R.N.; Minbiole, K. The cutaneous bacterium Janthinobacterium lividum inhibits the growth of Trichophyton rubrum in vitro. Int. J. Dermatol. 2015, 54, 156-159. [CrossRef]

41. Lam, B.A.; Walke, J.B.; Vredenburg, V.T.; Harris, R.N. Proportion of individuals with anti-Batrachochytrium dendrobatidis skin bacteria is associated with population persistence in the frog Rana muscosa. Biol. Conserv. 2010, 143, 529-531. [CrossRef]

42. Banas, J.A.; Loesche, W.J.; Nace, G.W. Classification and distribution of large intestinal bacteria in nonhibernating and hibernating leopard frogs (Rana pipiens). Appl. Environ. Microbiol. 1988, 54, 2305-2310. [CrossRef]

43. Christian, K.; Weitzman, C.; Rose, A.; Kaestli, M.; Gibb, K. Ecological patterns in the skin microbiota of frogs from tropical Australia. Ecol. Evol. 2018, 8, 10510-10519. [CrossRef]

44. Depoorter, E.; Bull, M.J.; Peeters, C.; Coenye, T.; Vandamme, P.; Mahenthiralingam, E. Burkholderia: An update on taxonomy and biotechnological potential as antibiotic producers. Appl. Microbiol. Biotechnol. 2016, 100, 5215-5229. [CrossRef]

45. Willems, A.; De Ley, J.; Gillis, M.; Kersters, K. NOTES: Comamonadaceae, a new family encompassing the acidovorans rRNA complex, including Variovorax paradoxus gen. nov., comb. nov., for Alcaligenes paradoxus (Davis 1969). Int. J. Syst. Bacteriol. 1991, 41, 445-450. [CrossRef]

46. Noel, A.C.; Guo, H.-Y.; Mandica, M.; Hu, D.L. Frogs use a viscoelastic tongue and non-Newtonian saliva to catch prey. J. R. Soc. Interface 2017, 14, 20160764. [CrossRef] [PubMed]

47. Lima, T.M.F. Descrição da Dieta de Melanophryniscus Admirabilis (Anura: Bufonidae). Bachelor's Thesis, Universidade Federal do Rio Grande do Sul, Porto Alegre, Brasil, 2014.

48. Trevelline, B.K.; Fontaine, S.S.; Hartup, B.K.; Kohl, K.D. Conservation biology needs a microbial renaissance: A call for the consideration of host-associated microbiota in wildlife management practices. Proc. R. Soc. B Boil. Sci. 2019, 286, 20182448. [CrossRef] [PubMed] 